\title{
Adding Pre-procedural Glycemia to the Mehran Score Enhances Its Ability to Predict Contrast- induced Acute Kidney Injury in Patients With and Without Diabetes Undergoing Percutaneous Coronary Intervention
}

\section{Annunziata Nusca ( $\square$ a.nusca@unicampus.it )}

Unit of Cardiovascular Science, Department of Medicine, Campus Bio-Medico University, Rome Via Alvaro del Portillo 200, 00128, Rome, Italy https://orcid.org/0000-0002-5616-3197

\section{Fabio Mangiacapra}

Campus Bio-Medico University of Rome

\section{Alessandro Sticchi}

Campus Bio-Medico University: Universita Campus Bio-Medico di Roma

Giovanni Polizzi

Campus Bio-Medico University: Universita Campus Bio-Medico di Roma Giulia D'Acunto

Campus Bio-Medico University: Universita Campus Bio-Medico di Roma Elisabetta Ricottini

Campus Bio-Medico University: Universita Campus Bio-Medico di Roma Rosetta Melfi

Campus Bio-Medico University: Universita Campus Bio-Medico di Roma Paolo Gallo

Campus Bio-Medico University: Universita Campus Bio-Medico di Roma Marco Miglionico

Campus Bio-Medico University: Universita Campus Bio-Medico di Roma

\section{Sara Giannone}

Campus Bio-Medico University: Universita Campus Bio-Medico di Roma

\section{Gian Paolo Ussia}

Campus Bio-Medico University: Universita Campus Bio-Medico di Roma

\section{Francesco Grigioni}

Campus Bio-Medico University: Universita Campus Bio-Medico di Roma 
Keywords: Glycemia, contrast-induced acute kidney injury, percutaneous coronary intervention, Mehran score, contrast media

Posted Date: October 2nd, 2020

DOI: https://doi.org/10.21203/rs.3.rs-84377/v1

License: (c) (1) This work is licensed under a Creative Commons Attribution 4.0 International License. Read Full License 


\section{Abstract}

Background: The Mehran score is the most widely accepted tool for predicting contrast-induced acute kidney injury (Cl-AKI), a major complication of percutaneous coronary intervention (PCI). Similarly, abnormal fasting pre-procedural glycemia (FPG) represents a modifiable risk factor for Cl-AKI, but it is not included in current risk models for $\mathrm{Cl}$-AKI prediction. We sought to analyze whether adding FPG to the Mehran score improves its ability to predict $\mathrm{Cl}-\mathrm{AKI}$ following PCl.

Methods: We analyzed 671 consecutive patients undergoing PCl (age $69[63,75]$ years, 23\% females), regardless of their diabetic status, to derive a revised Mehran score obtained by including FPG in the original Mehran score (Derivation Cohort). The new risk model (GlyMehr) was externally validated in 673 consecutive patients (Validation Cohort) (age $69[62,76]$ years, 21\% females).

Results: In the Derivation Cohort, both FPG and the original Mehran score predicted Cl-AKI (AUC 0.703 and 0.673 , respectively). The GlyMehr score showed a better predictive ability when compared with the Mehran score both in the Derivation Cohort (AUC 0.749, 95\% Cl 0.662-0.836; $p=0.0016$ ) and the Validation Cohort (AUC $0.848,95 \% \mathrm{Cl}, 0.792-0.903 ; p=0.0008)$. In the overall population $(n=1344)$, the GlyMehr score confirmed its independent and incremental predictive ability regardless of diabetic status $(p \leq 0.0034)$ or unstable/stable coronary syndromes $(p \leq 0.0272)$.

Conclusions: Adding FPG to the Mehran score significantly enhances our ability to predict Cl-AKI. The GlyMehr score may contribute to improve the clinical management of patients undergoing PCl by identifying those at high risk of $\mathrm{Cl}-\mathrm{AKI}$ and potentially detecting modifiable risk factors.

\section{Introduction}

The rate of contrast-induced acute kidney injury (Cl-AKI) has declined over the last decade (1-2), but it still represents a leading cause of in-hospital acquired renal insufficiency (3). In the specific setting of percutaneous coronary intervention (PCl), $\mathrm{Cl}$-AKI increases in-hospital and long-term mortality, exerting a deleterious impact on patients' outcome (4-6). The negative role of $\mathrm{Cl}-\mathrm{AKI}$ on post $\mathrm{PCl}$ outcome should not be a surprise, since a significant percentage of patients developing this complication do not completely recover their renal function, sometimes experiencing persistent renal insufficiency with potential need of dialysis (7).

The identification of patients at higher risk of $\mathrm{Cl}-\mathrm{AKI}$ prior to $\mathrm{PCl}$ is challenging, but necessary. In stable coronary artery disease, the potential advantages of $\mathrm{PCl}$ need to be weighed against the risk of renal insufficiency (8). In the setting of acute coronary syndromes, the risk of $\mathrm{Cl}$-AKI may provide indications when planning the extent of the revascularization to be achieved (9). After the procedure, the application of $\mathrm{Cl}-\mathrm{AKI}$ predictive scores could improve clinical management through tailored post-procedural monitoring and volume administration. 
The Mehran score is the most widely used tool for predicting $\mathrm{Cl}-\mathrm{AKI}$ following $\mathrm{PCl}$ (10-11). Pre-procedural hyperglycemia, regardless of the presence of diabetes, has also been associated with an increased risk of Cl-AKI (12-14), but it is not included in current risk scores.

The aim of the present study was to assess the potential incremental predictive value of adding fasting pre-procedural glycemia (FPG) to the Mehran score in identifying patients at higher risk of Cl-AKI after $\mathrm{PCl}$. The processes we used to derive and validate the score comply with the Tripod Statement (15).

\section{Methods}

\section{Study design and inclusion/exclusion criteria}

The study population was identified by searching the prospectively assembled institutional database of the catheterization laboratory of our Institution, enrolling patients undergoing $\mathrm{PCl}$ at the University Campus Bio-Medico of Rome from August 2016 through September 2019. Exclusion criteria were: STsegment elevation acute coronary syndromes, severe chronic kidney disease (defined as glomerular filtration rate, GFR $<15 \mathrm{ml} / \mathrm{min} / \mathrm{m}^{3}$ ), and peritoneal or hemodialytic treatment at the time of the procedure. The Derivation cohort consisted of the first 671 consecutive eligible patients undergoing PCI (from August 2016 through February 2018). The Validation cohort included the next 673 patients, sampled by the same investigators from a later time period (from March 2018 to September 2019) as contemplated by the Tripod statement (external validation) (15). The study was conducted in accordance with institutional guidelines, national and local legal requirements, and the Declaration of Helsinki.

\section{Coronary procedure}

Patients underwent $\mathrm{PCl}$ according to the standard techniques with radial or femoral approach. At the time of the procedure, all patients were receiving dual antiplatelet therapy with aspirin and clopidogrel or other novel antiplatelet agents maintained for a variable interval (1-12 months) according to the implanted stent type (bare metal stent versus drug-eluting stent) and/or clinical presentation. Routine hydration with normal saline at $1 \mathrm{ml} / \mathrm{hour} / \mathrm{kg}$ was performed in all patients with serum creatinine $(\mathrm{SCr})>1.3 \mathrm{mg} / \mathrm{dl}$ for at least 12 hours before and 24 hours after intervention; a reduced rate of $0.5 \mathrm{ml} / \mathrm{hour} / \mathrm{kg}$ was administered in those with reduced left ventricle ejection fraction (<40\%). PCI was performed using iodinated, lowosmolarity radiographic contrast agent (Iohexol, Omnipaque ${ }^{\mathrm{TM}}$, GE Healthcare AS).

\section{Model predictors and outcome}

Using standard methods, FPG was measured in all patients in the 2 hours prior to intervention. Two investigators blinded to glycemia data calculated the Mehran score as previously described (hypotension: 5 points; intra-aortic balloon pump - IABP- insertion: 5 points; congestive heart failure: 5 points; age $>75$ years: 4 points; anemia: 3 points; diabetes mellitus: 3 points; chronic renal failure: 4 points; contrast medium volume: 1 point for each $100 \mathrm{ml}$ ) (10). Patients were classified as having diabetes if their medical records reported a previous history of diabetes mellitus or any use of anti-diabetic agents. 
Anemia was defined as a hematocrit value $<39 \%$ for men and $<36 \%$ for women. Chronic renal disease was considered if baseline $\mathrm{SCr}>1.5 \mathrm{mg} / \mathrm{dl}$. Congestive heart failure was defined as the presence of congestive symptoms/signs (New York Heart Association Class III-IV) and left ventricle ejection fraction $\leq 40 \%$. Hypotension was considered as the occurrence of systolic pressure $<80 \mathrm{mmHg}$ for at least one hour requiring inotropic agents or IABP insertion within 24 of the $\mathrm{PCl}$.

The outcome of interest was the occurrence of Cl-AKI. Thus, SCr values were collected before the procedure, at 24 hours after $\mathrm{PCl}$, and thereafter if available. GFR was calculated using the Modification of Diet in Renal Disease (MDRD) Study equation. Cl-AKI was defined as an absolute increase in $\mathrm{SCr} \geq 0.3$ $\mathrm{mg} / \mathrm{dl}$ within 24-48 hours after contrast exposure (16). The diagnosis of $\mathrm{Cl}-\mathrm{AKI}$ was decided blinded to clinical information and the same definition was applied to the validation cohort.

\section{Sample size and missing data}

We did not calculate formal sample size because all available data were used to maximize the power of the results; however, there is no generally accepted approach to estimate sample size for derivation and validation studies of risk prediction models (15). No missing data related to either predictors or outcomes were observed in either the derivation cohort or the validation cohort.

\section{Statistical methods}

Data are expressed as frequencies and percentages for categorical variables and mean \pm standard deviation or median [Q1,Q3] for continuous variables. Normal distribution was evaluated by using the Shapiro-Wilk test. Differences between parametric and non-parametric continuous variables were tested with the Student $t$ test and Mann-Whitney $U$ test, respectively. Fisher exact test or Pearson $\chi^{2}$ test were used to compare categorical variables. Receiver operating characteristic (ROC) curve analysis was applied to estimate the ability of the Mehran score and FPG to discriminate between patients with and without $\mathrm{Cl}-\mathrm{AKI}$; their predictive validity was quantified as the area under the curve (AUC). In addition, the incremental value of combining the Mehran score and FPG together was assessed in predicting the primary end point. Therefore, AUC was calculated for the logistic regression model including both Mehran and FPG and differences between AUCs were assessed using the jackknife method, as described by DeLong et al (17). $\otimes$ Furthermore, net reclassification improvement (NRI) (based on 3 pre-specified risk categories: $<2 \%, 2-5 \%$, and $>5 \%$ ) was calculated to assess the predictive value of adding FPG to the Mehran score. Hence, a new risk score (GlyMehr) was developed in the Derivation cohort; it was built by adding baseline hyperglycemia, defined as a FPG $\geq 124 \mathrm{mg} / \mathrm{dl}$ (corresponding to the glycemic value with the highest sensitivity and specificity in predicting $\mathrm{Cl}-\mathrm{AKI}$ according to the ROC curve analysis), to the clinical and procedural variables included in the Mehran score. Both Mehran and FPG $\geq 124 \mathrm{mg} / \mathrm{dl}$ were entered in another multivariable logistic regression model to identify independent predictors of $\mathrm{Cl}-\mathrm{AKI}$ and, based on the $z$-score (model coefficient divided by SE), a weighted integer of 4 was assigned to FPG $\geq 124$ $\mathrm{mg} / \mathrm{dl}$. GlyMehr was calculated as the sum of the integers of each variable included in the original Mehran score plus that of $F P G \geq 124 \mathrm{mg} / \mathrm{dl}$. The discrimination ability of the GlyMehr score was assessed 
by ROC curve and associated AUC and by the index of separation (difference between the predicted probability of events in the group with the worst prognosis and the predicted probability of events in the group with the best prognosis). The calibration was evaluated using the Hosmer-Lemeshow goodness-offit test (the lower the $\chi 2$ value and the higher the $p$ value, the more calibrated the score) and by calculating the average absolute difference between the observed and the expected event rate across GlyMehr score tertiles (Mean $\Delta$; the lower the value, the better the calibration). The accuracy of the GlyMehr score was then tested on the Validation set. Furthermore, a pre-specified subgroup analysis on the overall population (Derivation and Validation cohorts) was performed to compare the discriminatory performance of the GlyMehr model with the original Mehran score according to the diabetic status and stable/unstable clinical presentation. Statistical analysis was performed using Stata/IC version 10.0 (STATA Corp, College Station, TX). A 2-tailed $P$ value $<0.05$ was considered significant.

\section{Results}

\section{Study population}

Baseline characteristics of the Derivation and Validation cohorts are reported in Table 1. Patients in the Validation cohort were more likely to have a diagnosis of dyslipidemia, probably related to the stricter cutoffs proposed for lipid management over time. Similarly, a reduced percentage of diabetic patients receiving insulin-therapy was reported in the Validation cohort and an increased use of novel anti-diabetic agents was observed.

\section{Predicting abilities of Mehran score and FPG in the Derivation cohort}

$\mathrm{Cl}-\mathrm{AKI}$ occurred in 30 patients (4.5\%) of the Derivation cohort. No patient required hemodialysis treatment. No sex-related difference was observed in Cl-AKI incidence.

Patients with Cl-AKI were more likely to have insulin-treated diabetes, chronic heart failure or anemia. Furthermore, they were more commonly hospitalized with a non-ST elevation acute coronary syndrome (NSTE-ACS) and received larger amounts of contrast media (Supplementary Table S1).

In the Derivation cohort, the original Mehran score significantly discriminated between patients with/without $\mathrm{Cl}-\mathrm{AKI}$ at ROC curve analysis (AUC $0.673 ; 95 \% \mathrm{Cl}, 0.580-0.765 ; \mathrm{p}=0.001$ ) (Supplementary Figure 1).

Patients with $\mathrm{Cl}-\mathrm{AKI}$ showed higher FPG levels $(\mathrm{p}=0.008)$. According to ROC curve, FPG meaningfully predicted Cl-AKI with an AUC of $0.703(95 \% \mathrm{Cl}, 0.589-0.817$; $p<0.001)$ (Supplementary Figure 1$)$. A preprocedural glycemic value $\geq 124 \mathrm{mg} / \mathrm{dl}$ was identified as the best cut-off to classify patients with postcontrast acute renal impairment (sensitivity $63.0 \%$, specificity $81 \%$ ). Patients with a pre-procedural glycemic value above this threshold reported an increased incidence of $\mathrm{Cl}-\mathrm{AKI}$, regardless of diabetic status $(p=0.013$ and $p<0.0001)$ (Figure 1$)$. 
By combining FPG with the Mehran score in the same logistic regression model for prediction of $\mathrm{Cl}-\mathrm{AKI}$, the AUC of the model significantly increased to $0.731(95 \% \mathrm{Cl}, 0.646-0.817 ; \mathrm{p}=0.022$ versus AUC of the Mehran score) (Supplementary Figure 1). The net reclassification improvement (NRI) [cutoff 2-5\%] was estimated at $0.319(p<0.001)$ (Supplementary Table S2).

\section{Performance of the new GlyMehr score in the Derivation cohort}

The revised risk score (GlyMehr) was built by adding FPG $\geq 124 \mathrm{mg} / \mathrm{dl}$, with a weighted integer of 4 , to the variables entering in the determination of the original Mehran score. The GlyMehr score ranged from 0 to 24 in the Derivation cohort, with a median value of 5 (lower quartile $<2$, upper quartile $>8$ ).

The GlyMehr score demonstrated a greater discrimination between patients with/without Cl-AKI compared with the original Mehran score (AUC 0.749; 95\% Cl, 0.662-0.836, p=0.0016 compared with Mehran AUC) (Figure 2). The index of separation was estimated to be $7.85 \%$ (9.26\%-1.41\%). An increase in predicted $\mathrm{Cl}-\mathrm{AKI}$ probability was also observed as the score increased (Supplemental Figure 2).

The GlyMehr score showed good calibration (Hosmer-Lemeshow, $p=0.183$ ) (mean $\Delta, 0.30 \%$ ). The distribution of patients with $\mathrm{Cl}-\mathrm{AKI}$ according to the Mehran and GlyMehr scores tertiles are reported in Figure 3.

\section{Performance of the GlyMehr score in the Validation cohort and Subgroup analysis}

The incidence of $\mathrm{Cl}-\mathrm{AKI}$ in the Validation cohort was 2.7\% (18 patients). Both the original Mehran and the GlyMehr scores were able to significantly classify patients with/without Cl-AKI (AUC $0.763 ; 95 \% \mathrm{Cl}$, 0.696- 0.829 for Mehran score; AUC, $0.848 ; 95 \%$ Cl, $0.792-0.903$ for GlyMehr score). Of note, the GlyMehr model showed a greater discriminatory performance compared with the original Mehran score in this cohort too ( $p=0.0008$ for AUC comparison).

Since the incidence of Cl-AKI was similar in the two cohort populations (Derivation and Validation), for descriptive purposes, we performed a subgroup analysis on the overall population consisting of 1344 patients.

In the overall cohort, the GlyMehr score confirmed a higher predicting ability compared with the Mehran score (AUC $0.787 ; 95 \% \mathrm{Cl}, 0.728-0.845$ for GlyMehr score, versus AUC $0.706 ; 95 \% \mathrm{Cl}, 0.642-0.770$ for Mehran score; $p<0.0001$ for AUC comparison). These results were confirmed in both diabetic and nondiabetic patients $(p=0.0034$ for AUC comparison among diabetics and $p=0.0012$ for AUC comparison among non-diabetic patients) and regardless of clinical presentation ( $p=0.0272$ for AUC comparison in patients with stable coronary artery disease and $p=0.0001$ for AUC comparison in the NSTE-ACS group) (Figure $4 \mathrm{~A}$ and $\mathrm{B}$ ).

\section{Discussion}


To the best of our knowledge, this is the first study including pre-procedural glycemia in a risk model for $\mathrm{Cl}-\mathrm{AKI}$ prediction in the specific setting of $\mathrm{PCl}$. We found that: 1) pre-procedural hyperglycemia is associated with an increased incidence of $\mathrm{Cl}-\mathrm{AKI} ; 2$ ) adding FPG to a pre-existing model for $\mathrm{Cl}$-AKI prediction such as the Mehran score to form the new GlyMehr score improves the performance in predicting this procedural complication.

\section{Hyperglycemia and Cl-AKI}

In our analysis, FPG alone significantly discriminated between patients with/without Cl-AKl; furthermore, those with pre-procedural hyperglycemia ( $\geq 124 \mathrm{mg} / \mathrm{dl}$ ) reported a higher incidence of this complication. Of note, the same glycemic cut-off ( $\geq 124 \mathrm{mg} / \mathrm{dl}$ ) was previously found as the best value for Cl-AKI prediction in a cohort of 421 patients with diabetes, pre-diabetes and normal fasting glucose undergoing coronary angiography (18).

Of course, these results highlight the importance of optimal glycemic control before and during $\mathrm{PCl}$, regardless of the presence of diabetes. Previous studies have already demonstrated the relationship between hyperglycemia and $\mathrm{Cl}-\mathrm{AKI}$ among patients with acute myocardial infarction undergoing primary $\mathrm{PCl}$ (12-14); nevertheless, to date few data were available in those receiving elective procedures.

Pathophysiological mechanisms underlying the association between elevated FPG and acute renal damage are not completely recognized. Therefore, whether hyperglycemia is a marker of increased comorbidity burden or the direct cause of $\mathrm{Cl}-\mathrm{AKI}$ is undetermined. Several investigations reported direct renal effects mediated by acute hyperglycemia. Acute hyperglycemia may reduce endothelial-mediated vasodilation and worsen medullary hypoxia due to a lower availability of nitric oxide (19). Acute hyperglycemia could also stimulate inflammation and reactive oxygen species synthesis, increasing contrast-induced injury on renal tubular cells (20).

Of note, in our population, the causes of hyperglycemia were unknown. While in diabetic patients high FPG could account for a not well-controlled diabetic status, different explanations may be considered in patients without diabetes, such as the lack of a previous diagnosis of the metabolic disorder or an acute response to stress, ischemia, infections or other chronic conditions. However, the focus of our investigation was to demonstrate the predictive value of pre-procedural glycemia on the incidence of $\mathrm{Cl}$ $A K I$, regardless of its specific cause.

\section{Cl-AKI prediction models: Mehran and GlyMehr}

In our study, the Mehran score was able to effectively identify patients who developed Cl-AKI both in the Derivation and Validation cohorts. This was expected since it represents a proven score for CI-AKI prediction $(10,11)$. However, several other predictive models have been validated for this purpose $(21-25)$. Some of these scores integrated an impressive number of variables needing complex algorithms to be calculated and have been proved in cohorts of patients undergoing primary $\mathrm{PCl}(21,22,24)$. Thus, we 
focused on the Mehran score taking into account its favorable balance between prediction accuracy and feasibility that represents one of the reasons for its widespread application in clinical practice.

However, in our analysis, combining FPG with the Mehran score in the new GlyMehr model revealed an even higher predictive ability for $\mathrm{Cl}-\mathrm{AKI}$. Higher values of GlyMehr score mean greater predicted probability and observed incidence of Cl-AKI. This is especially attractive if we consider that we obtained this result by adding a simple and easy parameter such as FPG.

Of note, like the Mehran score, most of the previously reported scores for $\mathrm{Cl}$-AKI prediction do not include FPG. Whether adding FPG to these models may also improve their performance is unknown and could be assessed in further studies. Nowadays, only one model counting FPG along with another twelve biochemical variables has recently been proposed, albeit based on a cohort of Chinese patients undergoing intra-arterial and intra-venous contrast administration for angiography and computer tomography (25).

The performance of the GlyMehr was greater compared with the original Mehran score also in the Validation cohort and in the overall population. Interestingly, according to the results of the subgroup analysis, the higher predictive ability of the new score was maintained both in diabetic and non-diabetic patients, suggesting that glycemic status might have a significant impact on outcomes also in those without an established diagnosis of diabetes. Similarly, previous studies reported a higher incidence of $\mathrm{Cl}-$ AKI in hyperglycemic patients without known diabetes in the setting of acute myocardial infarction $(12,13)$.

\section{Clinical implications}

$\mathrm{Cl}$-AKI represents one of the most common and serious non-cardiac complications in patients undergoing $\mathrm{PCl}$, together with bleeding. Despite a noteworthy decline of $\mathrm{Cl}-\mathrm{AKI}$ incidence over time, its negative prognostic impact has remained unchanged (4). This is even more important in view of the growing number of frail patients undergoing percutaneous procedures, who are potentially at higher risk of this complication.

On this background, the results of our analysis might be interesting. Considering a timely risk allocation for $\mathrm{Cl}-\mathrm{AKI}$ as an important goal, the use of the new score including FPG may improve the identification of patients at higher risk. Secondly, our findings might suggest a potential new strategy for the prevention of $\mathrm{Cl}-\mathrm{AKI}$, since pre-PCl glycemia may represent a modifiable intervention target.

Only a few pharmacological preventive strategies are currently available for $\mathrm{Cl}$-AKI prevention. Intense hydration still remains the cornerstone approach (26), whereas pre-treatment with high-dose statins has been shown to protect against the development of Cl-AKI in several randomized trials (27). The potential benefit of other agents has also been investigated with conflicting results (e.g., $\mathrm{N}$-acetylcysteine, sodium bicarbonate, ascorbic acid, xanthine) (28). Of note, none of these strategies has been demonstrated to lower the $\mathrm{Cl}-\mathrm{AKI}$ risk in patients with diabetes mellitus (28). 
Hence, restoring optimal glycemic control before $\mathrm{PCl}$ in order to provide a new prophylactic approach in preventing $\mathrm{Cl}-\mathrm{AKI}$ is worthy of further investigation. Strict glycemic control with insulin has been demonstrated to reduce the occurrence of acquired kidney injury (29). More recently, sodium-glucose transport protein 2 (SGLT2) inhibitors, a new class of glucose-lowering agents acting by promoting glycosuria, have demonstrated protective renal effects (30-32). Furthermore, these agents seem to significantly decrease the risk of acute kidney injury in diabetic patients (33). However, no data are available on a possible benefit regarding $\mathrm{Cl}-\mathrm{AKI}$, and it is also unknown whether SGLT2 inhibitors may exert their renoprotective effects also in patients without diabetes.

\section{Strengths And Limitations}

We defined $\mathrm{Cl}$-AKI using the baseline and the peak SCr (24 or 48 hours after contrast use). Thus, Cl-AKI occurrence may be underestimated since we cannot exclude the possibility that $\mathrm{SCr}$ reached its peak after discharge. However, we checked 48-hour SCr in all patients with even a mild increase at 24 hours and, as previously reported, even a slight ( 5 to $10 \%$ from baseline) SCr increase within 24 hours after the coronary procedure could predict $\mathrm{Cl}-\mathrm{AKI}$ occurrence with a high negative predictive value (34). We did not serially evaluate blood glucose levels in our patients, thus we do not know if an early spontaneous or pharmacological normalization of glycemic values was associated with a lower incidence of Cl-AKI. However, our investigation may represent a hypothesis-generating study for further randomized studies exploring this issue. We validated the new risk score in a cohort of patients undergoing PCl for stable and unstable syndromes, but excluding patients with ST-elevation myocardial infarction. Thus, we have no data on the discriminatory performance of the GlyMehr score in the setting of primary PCl. However, hyperglycemia, as previously demonstrated, may have an even more important role for the development of $\mathrm{Cl}-\mathrm{AKI}$ after acute procedures.

\section{Conclusions}

Recognition of new potential risk factors for Cl-AKI may allow early identification of patients at higher risk for this complication and possible future therapeutic targets. Adding FPG, an easily available and inexpensive marker, to procedural and clinical variables of the Mehran score in a new model increases the predictive value for $\mathrm{Cl}-\mathrm{AKI}$ compared with the Mehran score alone. Whether the GlyMehr may have a longterm prognostic role or whether specific tailored glucose-lowering interventions may reduce $\mathrm{Cl}-\mathrm{AKI}$ incidence should be addressed in further studies.

\section{Abbreviations}

$\mathrm{Cl}-\mathrm{AKI}=$ contrast-induced acute kidney injury

$\mathrm{PCl}=$ percutaneous coronary intervention

$\mathrm{SCr}=$ serum creatinine 
$F P G=$ fasting pre-procedural glycemia

NYHA = New York Heart Association

IABP = intra-aortic balloon pump

GFR = glomerular filtration rate

$\mathrm{ROC}=$ receiver operating characteristic

AUC $=$ area under the curve

$\mathrm{NRI}=$ net reclassification improvement

\section{Declarations}

\section{Ethics approval and consent to participate}

Thus study was performed in accordance with the Declaration of Helsinki and has been approved by our local Ethic Committee (Ethical Committee of Campus Bio-Medico University of Rome). Due to the retrospective nature of this analysis performed by searching the prospectively assembled institutional database of the catheterization laboratory of our Institution, the requirement for patients' written informed consent was considered not necessary; however, all patients gave their agreement for the interventional procedure at the time of revascularization according to current guidelines.

\section{Consent for publication}

Not applicable

\section{Availability of data and materials}

The authors declare that all data supporting the findings of this study are available within the article and its supplementary information files.

\section{Competing interests}

The authors declare that they have no potential conflicts of interest relevant to this article.

\section{Funding}

The authors did not receive any financial support for the research, authorship, and/or publication of this article.

\section{Author Contributions}


A.N. contributed to the conception and design of the study, to the interpretation of the data and wrote the manuscript. F.M. contributed to the study design, statistical analysis and data interpretation and supported the writing of the manuscript. A.S., G.P., G.D. and S.G. contributed to data acquisition. E.R., R.M., P.G. and M.M. supported the statistical analysis and reviewed the manuscript. G.P.U. and F.G. reviewed/edited the manuscript. All authors read, commented, and approved the final version of the manuscript. A.N. is the guarantor of this work and, as such, had full access to all the data in the study and takes responsibility for the integrity of the data and the accuracy of the data analysis.

\section{Acknowledgments}

The authors thank all medical and nursing staff of Campus Bio-Medico University of Rome for patient enrollment and assessment.

\section{References}

1. Amin AP, Salisbury AC, McCullough PA, Gosch K, Spertus JA, Venkitachalam L, et al. Trends in the incidence of acute kidney injury in patients hospitalized with acute myocardial infarction. Arch Intern Med. 2012;172:246-53.

2. Tsai TT, Patel UD, Chang TI, KennedyKF, Masoudi FA, Matheny ME, et al. Contemporary incidence, predictors, and outcomes of acute kidney injury in patients undergoing percutaneous coronary interventions: insights from the NCDR Cath-PCI Registry. J Am Coll Cardiol Interv. 2014;7:1-9.

3. Lameire N, Van Biesen W, Vanholder R. Acute renal failure. 2005;365:417-30.

4. Giacoppo D, Madhavan MV, Baber U, Warren J, Bansilal S, Witzenbichler B, et al. Impact of contrastinduced acute kidney injury after percutaneous coronary intervention on short- and long-term outcomes: pooled analysis from the HORIZONS-AMI and ACUITY Trials. Circ Cardiovasc Interv. 2015;8:e002475.

5. Sadeghi HM, Stone GW, Grines CL, Mehran R, Dixon SR, Lansky AJ, et Impact of renal insufficiency in patients undergoing primary angioplasty for acute myocardial infarction. Circulation. 2003;108:276975.

6. Rihal CS, Textor SC, Grill DE, Berger PB, Ting HH, Best PJ, et al. Incidence and prognostic importance of acute renal failure after percutaneous coronary intervention. Circulation. 2002;105:2259-64.

7. James MT, Ghali WA, Tonelli M, Faris P, Knudtson ML, Pannu N, et al. Acute kidney injury following coronary angiography is associated with a long-term decline in kidney function. Kidney Int. 2010;78:803-9.

8. BangaloreS, Maron DJ, O'Brien SM, Fleg JL, Kretov El, Briguori C, et al. Management of Coronary Disease in Patients With Advanced Kidney Disease. N Engl J Med. 2020;382(17):1608-18.

9. Wood DA, Cairns JA, Wang J, Mehran R, Storey RF, Nguyen H, et al. Timing of Staged Nonculprit Artery Revascularization in Patients With ST-Segment Elevation Myocardial Infarction. J Am Coll Cardiol. 2019;74(22):2713-23. 
10. Mehran R, Aymong ED, Nikolsky E, Lasic Z, lakovou I, Fahy M, et al. A simple risk score for prediction of contrast-induced nephropathy after percutaneous coronary intervention: development and initial validation. J Am Coll Cardiol. 2004;44:1393-99.

11. Sgura FA, Bertelli L, Monopoli D, Leuzzi C, Guerri E, Spartà I, et al. Mehran contrast-induced nephropathy risk score predicts short- and long-term clinical outcomes in patients with ST-elevationmyocardial infarction. Circ Cardiovasc Interv. 2010;3:491-98.

12. Marenzi G, De Metrio M, Rubino M, Lauri G, Cavallero A, Assanelli E, et al. Acute hyperglycemia and contrast-induced nephropathy in primary percutaneous coronary intervention. Am Heart $\mathrm{J}$. 2010;160:1170-77.

13. Stolker JM, McCullough PA, Rao S, Inzucchi SE, Spertus JA, Maddox TM, et al. Pre-procedural glucose levels and the risk for contrast-induced acute kidney injury in patients undergoing coronary angiography. J Am Coll Cardiol. 2010;55:1433-40.

14. Naruse H, Ishii J, Hashimoto T, Kawai T, Hattori K, Okumura M, et al. Pre-procedural glucose levels and the risk for contrast-induced acute kidney injury in patients undergoing emergency coronary intervention. Circ J. 2012;76(8):1848-55.

15. Moons KG, Altman DG, Reitsma JB, loannidis JP, Macaskill P, Steyerberg EW, et al. TransparentReporting of a multivariable prediction model for IndividualPrognosis or Diagnosis (TRIPOD): explanation and Ann Intern Med. 2015;162(1):W1-73.

16. Mehta RL, Kellum JA, Shah SV, Molitoris BA, Ronco C, Warnock DG, et al. Acute kidney injury network: report of an initiative to improve outcomes in acute kidney injury. Crit Care. 2007;11:R31.

17. DeLong ER, DeLong DM, Clarke-Pearson DL. Comparing the areas under two or more correlated receiver operating characteristic curves: a nonparametric approach. Biometrics. 1988;44:837-45.

18. Toprak O, Cirit M, Yesil M, Bayata S, Tanrisev M, Varol U, et al. Impact of diabetic and pre-diabetic state on development of contrast-induced nephropathy in patients with chronic kidney disease. Nephrol Dial Transplant. 2007;22:819-26.

19. Gomes MB,Affonso FS, Cailleaux S, Almeida AL, Pinto LF, Tibiriçá E. Glucose levels observed in daily clinical practice induce endothelial dysfunction in the rabbit macro- and microcirculation. Fundam Clin Pharmacol. 2004;18(3):339-46.

20. Wang JY, Yang JH, Xu J, Jia JY, Zhang XR, Yue XD, et al. Renal tubular damage may contribute more to acute hyperglycemia induced kidney injury in non-diabetic conscious rats. J Diabetes Complications. 2015;29(5):621-28.

21. Tsai TT, Patel UD, Chang TI, Kennedy KF, Masoudi FA, Matheny ME, et al. Validated contemporary risk model of acute kidney injury in patients undergoing percutaneous coronary interventions: insights from the National Cardiovascular Data Registry Cath-PCI Registry. J Am Heart Assoc 2014;3(6):e001380.

22. Andò G, Morabito G, de Gregorio C, Trio O, Saporito F, Oreto G. The ACEF score as predictor of acute kidney injury in patients undergoing primary percutaneous coronary intervention. Int $J$ 
Cardiol2013;168(4):4386-87.

23. Chen YL, Fu NK, Xu J, Yang SC, Li S, Liu YY, et al. A simple preprocedural score for risk of contrastinduced acute kidney injury after percutaneous coronary intervention. Catheter Cardiovasc Interv. 2014;83(1):E8-16.

24. Inohara T, Kohsaka S, Abe T, Miyata H, Numasawa Y, Ueda I, et al. Development and validation of a pre-percutaneous coronary intervention risk model of contrast-induced acute kidney injury with an integer scoring system. Am J Cardiol. 2015;115(12):1636-42.

25. Yin WJ, Yi YH, Guan XF, Zhou LY, Wang JL, Li DY, et al. Preprocedural prediction model for contrastinduced nephropathy patients. J Am Heart Assoc. 2017;6:e004498.

26. Neumann FJ,Sousa-Uva M, Ahlsson A, Alfonso F, Banning AP, Benedetto U, et al. 2018 ESC/EACTS Guidelines on myocardial revascularization. Eur Heart J. 2019;40(2):87-165.

27. Li H, Wang C, Liu C, Li R, Zou M, Cheng G. Efficacy of Short-Term Statin Treatment for the Prevention of Contrast-Induced Acute Kidney Injury in Patients Undergoing Coronary Angiography/Percutaneous Coronary Intervention: A Meta-Analysis of 21 Randomized Controlled Trials. Am J Cardiovasc Drugs. 2016;16(3):201-19.

28. Giacoppo D, Gargiulo G, Buccheri S, Aruta P, Byrne RA, Cassese S, et al. Preventive Strategies for Contrast-Induced Acute Kidney Injury in Patients Undergoing Percutaneous Coronary Procedures: Evidence From a Hierarchical Bayesian Network Meta-Analysis of 124 Trials and 28240 Patients. Circ Cardiovasc Interv. 2017;10(5):e004383.

29. Schetz M, Vanhorebeek I, Wouters PJ, Wilmer A, Van den Berghe G. Tight blood glucose control is renoprotective in critically ill patients. J Am Soc Nephrol. 2008;19(3):571-78.

30. Wanner C, Inzucchi SE, Lachin JM, Fitchett D, von Eynatten M, Mattheus M, et al. Empagliflozin and Progression of Kidney Disease in Type 2 Diabetes. N Engl J Med. 2016;375(4):323-34.

31. Neal B, Perkovic V, Mahaffey KW, de Zeeuw D, Fulcher G, Erondu N, et al. Canagliflozin and Cardiovascular and Renal Events in Type 2 Diabetes. N Engl J Med. 2017;377(7):644-57.

32. Mosenzon O, Wiviott SD, Cahn A, Rozenberg A, Yanuv I, Goodrich EL, al. Effects of dapagliflozin on development and progression of kidney disease in patients with type 2 diabetes: an analysis from the DECLARE-TIMI 58 randomised trial. Lancet Diabetes Endocrinol. 2019;7:606-17.

33. Nadkarni GN, Ferrandino R, Chang A, Surapaneni A, Chauhan K, Poojary P, et al. Acute Kidney Injury in Patients on SGLT2 Inhibitors: A Propensity-Matched Analysis. Diabetes Care. 2017; 40(11):1479-85.

34. Ribichini F, Graziani M, Gambaro G, Pasoli P, Pighi M, Pesarini G, et al. Early creatinine shifts predict contrast-induced nephropathy and persistent renal damage after angiography. Am J Med. 2010;123(8):755-63.

\section{Tables}

Table1. Baseline characteristics of the Derivation and Validation cohorts 


\begin{tabular}{|c|c|c|c|c|}
\hline & $\begin{array}{l}\text { Overall } \\
(n=1344)\end{array}$ & $\begin{array}{l}\text { Derivation } \\
(n=671)\end{array}$ & $\begin{array}{l}\text { Validation } \\
(n=673)\end{array}$ & $P$ value \\
\hline Age (years) & $69[63,76]$ & $69[63,75]$ & $69[62,76]$ & 0.314 \\
\hline Female gender & $292(22)$ & $153(23)$ & $139(21)$ & 0.340 \\
\hline BMI $\left(\mathrm{kg} / \mathrm{m}^{2}\right)$ & $26[24,30]$ & $27[25,30]$ & $26[24,30]$ & 0.105 \\
\hline Dyslipidemia & $1180(88)$ & $548(82)$ & $632(94)$ & $<0.001$ \\
\hline Hypertension & $1210(90)$ & $603(90)$ & $607(90)$ & 0.841 \\
\hline Diabetes & $464(35)$ & $248(37)$ & $216(32)$ & 0.060 \\
\hline Insulin-treated & $87(6)$ & $62(9)$ & $25(4)$ & $<0.001$ \\
\hline Smoking & $888(66)$ & $470(70)$ & $418(62)$ & $<0.001$ \\
\hline NSTE-ACS & $487(36)$ & $227(34)$ & $260(39)$ & 0.067 \\
\hline Multivessel disease & $639(48)$ & $309(46)$ & $330(49)$ & 0.825 \\
\hline LVEF (\%) & $55.2 \pm 9.0$ & $55.4 \pm 8.8$ & $55.0 \pm 9.2$ & 0.373 \\
\hline Congestive heart failure & $73(5)$ & $33(5)$ & $40(6)$ & 0.407 \\
\hline Hemoglobin (g/dl) & $13.2[12.1,14.4]$ & $13.2[12.0,14.3]$ & $13.3[12.2,14.4]$ & 0.138 \\
\hline Hematocrit (\%) & $39.7[36.9,42.7]$ & $39.6[36.6,42.7]$ & $39.8[37.1,42.8]$ & 0.202 \\
\hline Anemia & $479(36)$ & $245(37)$ & $234(35)$ & 0.505 \\
\hline Creatinine (mg/dl) & $0.94[0.80,1.12]$ & $0.94[0.80,1.12]$ & $0.94[0.81,1.11]$ & 0.814 \\
\hline GFR $\left(\mathrm{ml} / \mathrm{min} / 1.73 \mathrm{~m}^{2}\right)$ & $68.9[46.3,85.0]$ & $67.2[45.4,84.6]$ & $69.7[48.8,85.6]$ & 0.263 \\
\hline Chronic kidney disease & $75(6)$ & $39(6)$ & $36(5)$ & 0.716 \\
\hline FPG $(\mathrm{mg} / \mathrm{dl})$ & $99[89,116]$ & $100[89,118]$ & $98[89,113]$ & 0.132 \\
\hline Statins & $1142(85)$ & $577(86)$ & $565(84)$ & 0.296 \\
\hline Beta-blockers & $921(69)$ & $470(70)$ & $451(67)$ & 0.232 \\
\hline ACE-inhibitors & $1082(81)$ & $550(82)$ & $532(79)$ & 0.177 \\
\hline Diuretics & $502(37)$ & $260(39)$ & $242(36)$ & 0.290 \\
\hline Calcium-channel inh. & $522(39)$ & $266(40)$ & $256(38)$ & 0.546 \\
\hline Biguanides & $302(22)$ & $161(24)$ & $141(21)$ & 0.181 \\
\hline Sulfonylureas & $135(10)$ & $74(11)$ & $61(9)$ & 0.231 \\
\hline Meglitinides & $61(4.5)$ & $34(5)$ & $27(4)$ & 0.353 \\
\hline
\end{tabular}




\begin{tabular}{|lllll|}
\hline SGLT2 inhibitors & $67(5.0)$ & $20(3)$ & $47(7)$ & $<0.001$ \\
\hline DPP-4 inhibitors & $88(6.5)$ & $27(4)$ & $61(9)$ & $<0.001$ \\
\hline GLP-1 receptor agonists & $65(4.8)$ & $2(0.3)$ & $63(9)$ & $<0.001$ \\
\hline Contrast volume $(\mathrm{ml})$ & $150[118,200]$ & $150[116,200]$ & $150[120,193]$ & 0.892 \\
\hline Hypotension & $9(0.7)$ & $3(0.4)$ & $6(0.9)$ & 0.318 \\
\hline IABP & 0 & 0 & 0 & - \\
\hline Cl-AKI & $48(3.6)$ & $30(4.5)$ & $18(2.7)$ & 0.076 \\
\hline Mehran score & $4[1,7]$ & $4[1,7]$ & $4[2,7]$ & 0.793 \\
\hline
\end{tabular}

Values are mean $\pm \mathrm{SD}$, median $[\mathrm{Q} 1, \mathrm{Q} 3]$ or $\mathrm{n}(\%)$.

$\mathrm{ACE}$, angiotensin-converting enzyme; $\mathrm{BMI}$, body mass index; $\mathrm{Cl}-\mathrm{AKI}$, contrast-induced acute kidney injury; DPP-4, dipeptidylpeptidase-4; FPG, fasting pre-procedural glycemia; GLP-1, glucagon-like peptide-1; GFR, glomerular filtration rate; IABP, intra-aortic balloon pump; LVEF, left ventricular ejection fraction; NSTEACS, non-ST elevation acute coronary syndrome; SGLT2, sodium-glucose transporter-2.

\section{Figures}




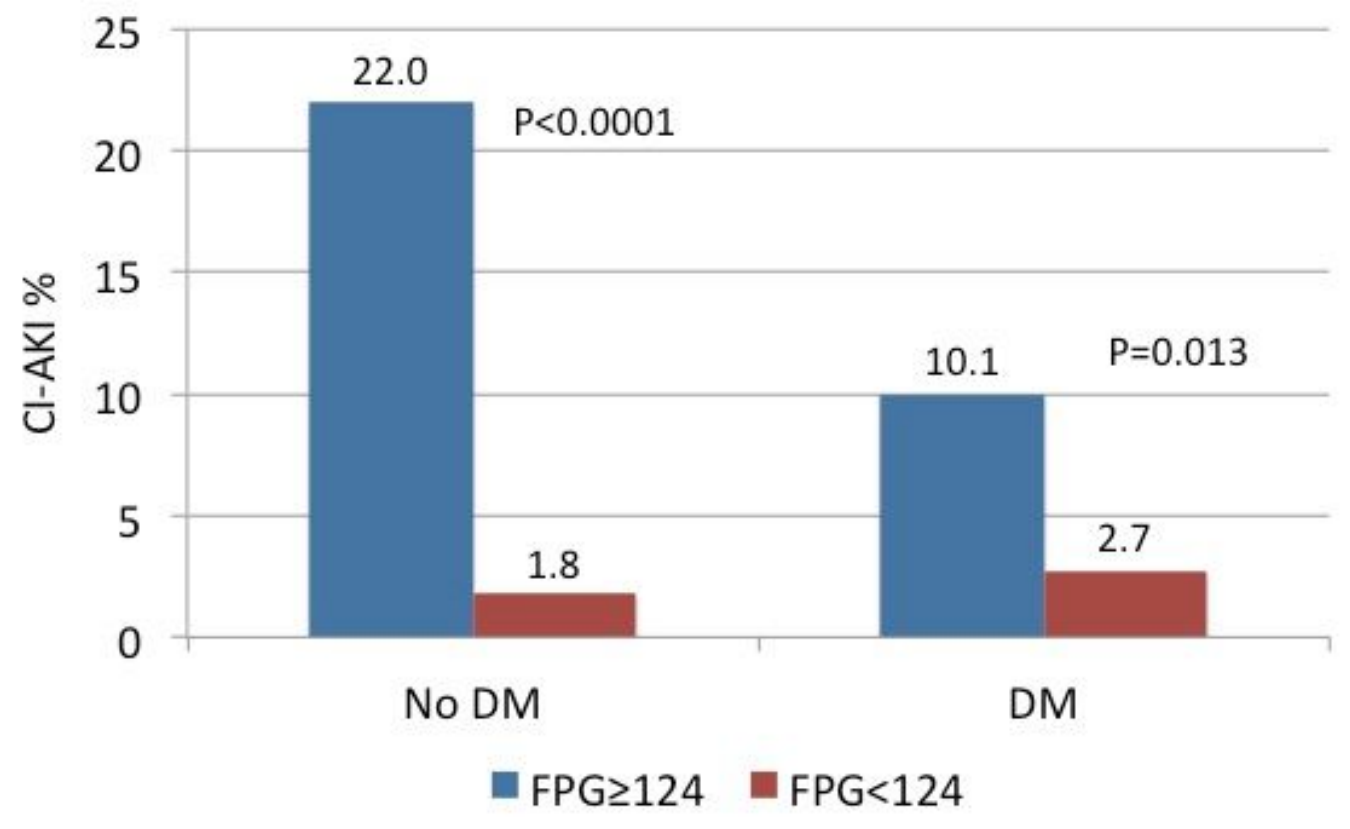

Figure 1

Title: Incidence of Cl-AKI according to pre-procedural glycemia. Legend: Cl-AKI occurrence in patients with $\mathrm{FPG} \geq 124 \mathrm{mg} / \mathrm{dl}$ and FPG $<124 \mathrm{mg} / \mathrm{dl}$ among diabetics and non-diabetics. $\mathrm{Cl}-\mathrm{AKI}=$ contrast-induced acute kidney injury; $F P G=$ fasting pre-procedural glycemia; $D M=$ diabetes mellitus. 


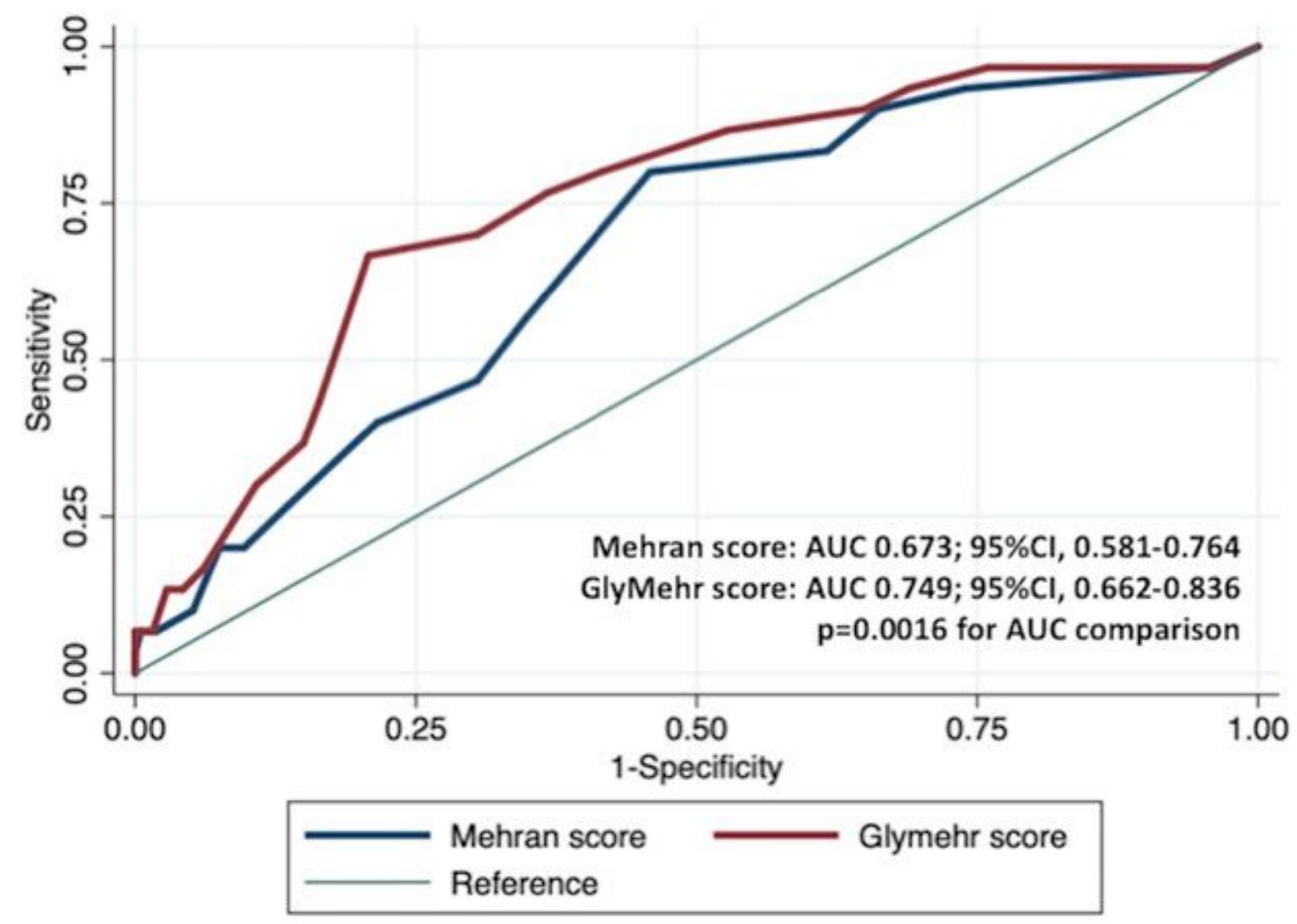

Figure 2

Title: Mehran and GlyMehr scores for the prediction of Cl-AKI. Legend: Comparison of receiver operating characteristic curves for $\mathrm{Cl}-\mathrm{AKI}$ between Mehran and GlyMehr scores in the Derivation cohort. Cl-AKI= contrast-induced acute kidney injury. 


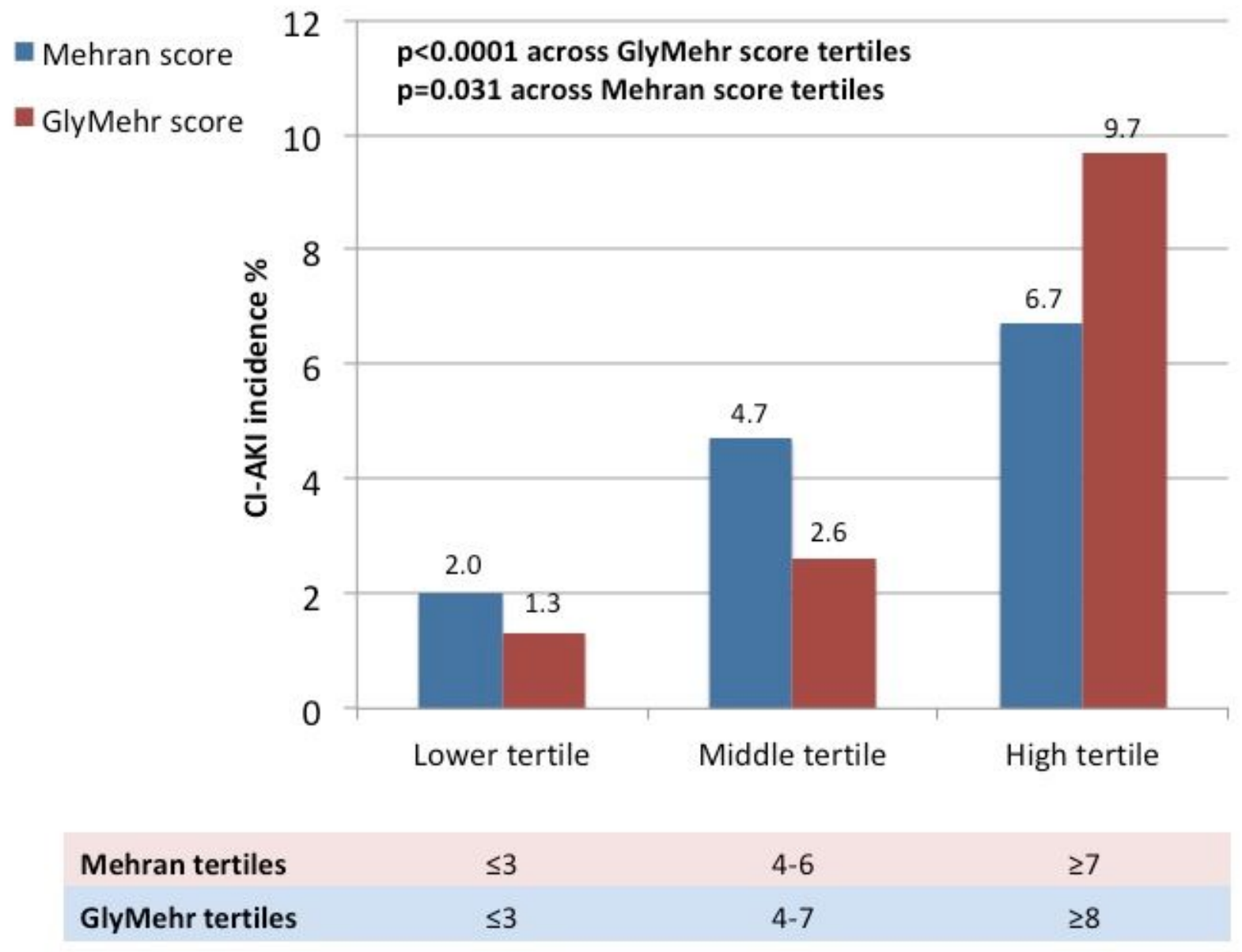

\section{Figure 3}

Title: Incidence of Cl-AKI according to the Mehran and GlyMehr scores tertiles. Legend: In the Derivation cohort an increased incidence of Cl-AKI was observed in the highest tertile of the GlyMehr score compared with the highest tertile of the Mehran score, suggesting a greater prediction accuracy of the new model. $\mathrm{Cl}-\mathrm{AKI}=$ contrast-induced acute kidney injury. 

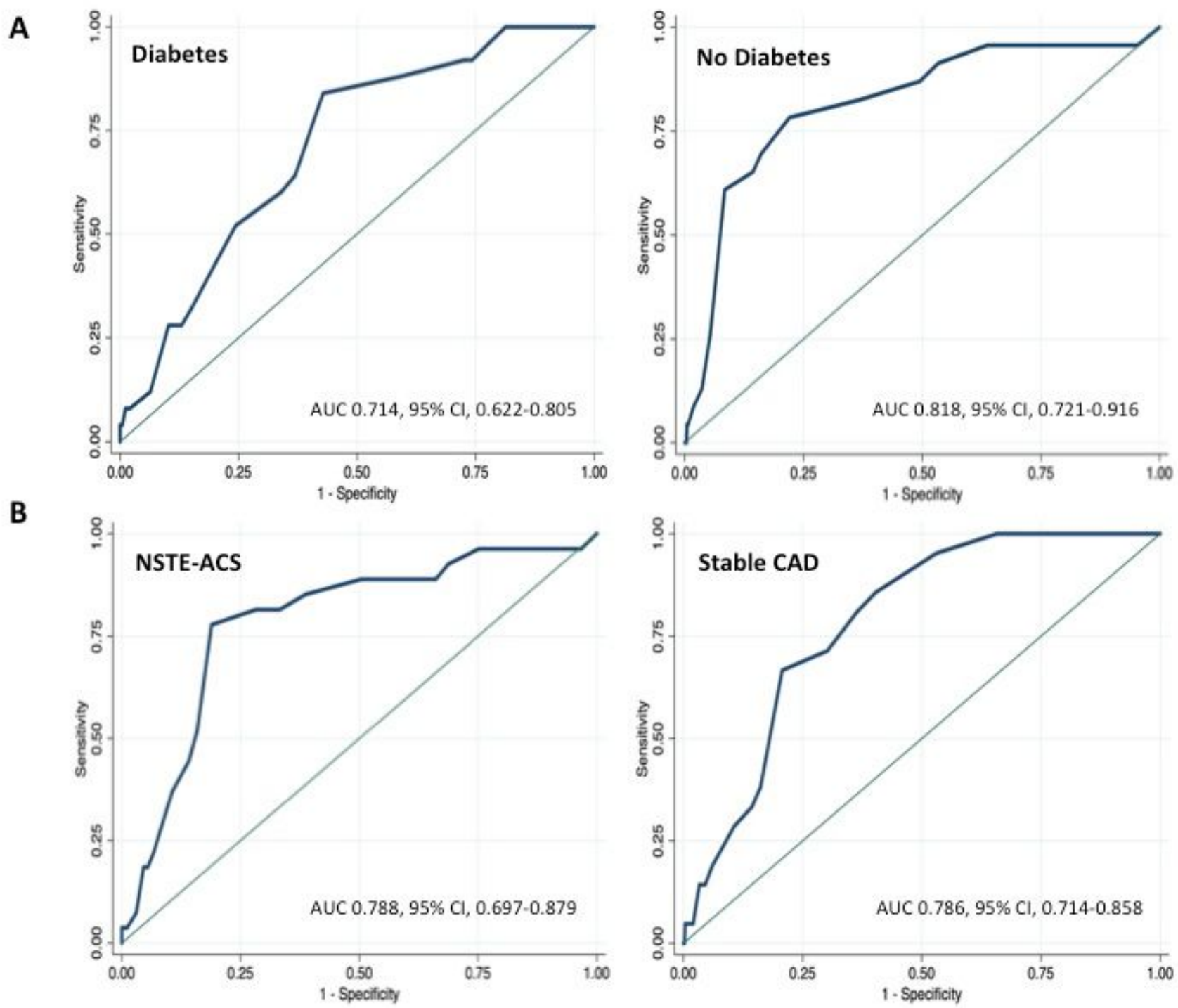

\section{Figure 4}

Title: Cl-AKI prediction ability of the GlyMehr score according to diabetic status or unstable/stable coronary syndromes. Legend: A - Receiver operating characteristic curves of the GlyMehr score in diabetic and not-diabetic subgroups $(p=0.0034$ for AUC comparison with Mehran score among diabetics and $p=0.0012$ for AUC comparison among non-diabetic patients). B - Receiver operating characteristic curves of the GlyMehr score in patients with NSTE-ACS and stable CAD ( $p=0.0001$ and $p=0.0272$ for AUC comparison with Mehran score in the NSTE-ACS and stable CAD subgroups, respectively). CAD= coronary artery disease; $\mathrm{Cl}-\mathrm{AKI}=$ contrast-induced acute kidney injury; NSTE-ACS= non-ST elevation acute coronary syndromes.

\section{Supplementary Files}

This is a list of supplementary files associated with this preprint. Click to download.

- Additionalfile1.docx 
- Additionalfile2.TripodChecklist.pdf 